\title{
Research on Profit Model of Long Tail Product in China's Video Websites Lin Shi
}

School of economics and management, Communication University of China, Beijing 100024, China

Keywords: Long tail, Video website.

\begin{abstract}
China's video site industry mainly through direct advertising, membership services, subscription-on-demand and copyright sales to obtain revenue, although the development of many years still face the challenges of profitability. The application of long tail theory in management helps to improve the profitability of Internet companies and applies to the operation of video websites. The long-tail resource management mainly through the operating income and cost of sales of two factors affect the profitability of video sites, this paper for these two factors, it is recommended that enterprises should integrate the existing resources and improve the database information, optimize the search and recommendation engine and through large data Analysis of the user accurate delivery of search results, through the induction of the use of Matthew effect to change the head, and reshape the industrial chain, to explore new business models.
\end{abstract}

\section{Introduction}

With Google in October 2006 priced at 1.65 billion acquisition of video sites YouTube, video site investment value into the eyes of more investors, but also in China's Internet industry set off a wave of registration and investment video sites. Data show that in early 2006, China's video sites less than 30, and the current industry has reached hundreds of competitors, many of which Youku, Letv and iQiyi to attract a large number of funds stationed in the leader. However, at present, these video sites are reflected in the profitability are very limited: love odd art year after year loss, Youku Tudou 2015 loss of 20 billion yuan; music as 2015 main business income of 13.016 billion, net profit after tax of 217 million, but its operating profit is only 069 million, total profit of 74 million, operating profit margin of only $0.53 \%$.

Overall, China's video site industry has produced more than 10 years, in the huge investment and the rapid development of the Internet on the basis of cultivating a large user groups, but still did not form a mature and effective profit mechanism. How the video site profit, is still nowadays business operators and investors concerned about and explore the topic.

\section{The main source of revenue for video sites}

Video website revenue mainly from advertisers, users and other industry participants, in accordance with the nature of business behavior and charging model, can be divided into patch advertising, membership services, on demand and copyright sales of four parts.

\section{Pre-rolls}

In-store advertising and charge related fees is the traditional revenue-generating methods of various types of video services, is also an important source of video revenue, and is still considered a high room for growth. YouTube's advertising revenue grew by more than 50\% between 2012 and 2014, 
and advertising revenue was the main source of \$ 9 billion in revenue for 2015. Music Watch's advertising revenue by 2015 was about $\$ 2.6$ billion, accounting for $20 \%$ of revenue $68 \%$.

In 2015, China's online advertising market size reached 203.4 billion yuan, an increase of 36\%, with the development of online advertising market continues to mature, is expected to 2018 the overall size is expected to exceed 400 billion yuan, of which video patch advertising benefit from China Mobile Communications Technology Of the rapid development and application of mobile applications continue to develop, the share will continue to expand, the overall size is expected to grow from 16 billion yuan in 2015 to 2018 yuan 36 billion yuan.

\section{Membership service}

With the improvement of the online video copyright environment, video sites can increase the quality of advertising without reducing the loss of users, which reduces the quality of the site operators, while the user experience has a negative impact on the user experience, but also gave birth to a new consumer Demand - Member Services.

Through the payment of membership fees, users can get free advertising, high-definition video, royalty download, high-speed download channel and other privileges, or even give priority to a few days to enjoy the copyright is not fully open programs, such as premiere TV drama - through the exclusive drama Descendants of the Sun, iQiyi pulled 5 million paid membership to join; Letv the investment by more than 20 million yuan of the Go Princess Go in the right to launch the 2.2 million new members.

\section{VOD with charge}

Many sites are also committed to providing independent video charging on demand. In the film, Letv, Tencent and other seven Internet companies jointly launched the establishment of the film network cinema distribution alliance, boost the Internet to become the film's second largest distribution channel; in sports events, Letv sports channel and other network sports video The platform offers a variety of copyrighted games, which attracts a large number of sports enthusiasts.

Increasingly high-quality copyrighted content increases the willingness of users to pay for monthly services and pay-per-view services, allowing video sites to shift from simply relying on advertising revenue to the mode of operation in which advertising and user-paid revenue models coexist. For example, the total income of pay-as-you-paid business by 2015 will be RMB2.71 billion, up by $77.60 \%$ year on year, and it will become a new profit growth point with the advertising business.

\section{Copyright sale}

In addition to advertising and users from the two channels, the sale of copyright and sales to the industry, but also the way the video site revenue, mainly "buy + sales" and "production + sales" two business models.

"Buy + sales" refers to the video site one-time buyout TV series, the film's online copyright, and then sold to other competitive enterprises. This is a business model to protect their own right to broadcast, to ensure that the user's attraction; the second is to ease the expansion of the enterprise to buy copyright caused by the pressure; third is to reduce the other video sites to buy exclusive copyright cost pressures.

"Production + sales" refers to the video site to produce their own, to provide professional production content, in addition to broadcast on their own website, but also to other companies to do embedded or provide resources to charge the corresponding copyright fees.

From the domestic market, copyright sales were the most important source of operating income, almost half of its operating income in 2012 to 50\%. But this income model behind a huge investment and risk, in the absence of strong financial support, the general business is difficult to use it as a sustained profit growth point. 


\section{Application of Long Tail Theory in Video Website}

\section{The development of long tail theory}

Chris Anderson put forward the long tail theory, which "if enough non-hot products together, in fact, can form a comparable to the popular market matches the big market." At the same time, due to the development of the Internet, access to non-hot product information becomes economical and convenient for the formation of this market may bring.

The effect of long tail theory is demonstrated in the observation of Amazon, Google and many other Internet companies. With the promotion of the Internet, effective user needs and access to the channel compared with the traditional business model has undergone significant changes.

\section{Long tail theory applies to video site operations}

In the traditional video market, limited by the broadcast time of the television station, limited shelf space and other factors, only the "popular" program products can be seen by the audience, some because of age, professional or other reasons and more small minority Video and programs will not be displayed in front of the audience, the audience even if there is no need to find these products. But in the video site, these previously ignored a variety of niche programs, forming a "long tail" of the market.

\section{The Factors Influencing the Profit of Long Tail Video Resources}

To consider the impact of long-tailed video resource profit factors, the video website should be from the general profit factors to find long-tailed video resources related aspects.

In general, the profits of video website companies can be summarized as follows:

Net profit $=$ total operating income - total operating cost + investment income + non-operating income - non-operating expenses - income tax expense

Among them, the independent consideration of long-tailed video resources on the impact of video site profits, due to the video site, the long tail video resources management, use and operation of the video site is the main business, so to highlight the focus, Only the revenue and operating costs arising from the revenue and operating costs arising from the two aspects: the source of income is mainly reflected in the advertising business income, paid business income and copyright business income; cost is mainly reflected in the sales costs, management fees, financial expenses and depreciation as intangible assets. The sales expenses mainly refer to the advertising promotion fee, the membership fee, the logistics sale and other related office expenses and labor costs arising from the sales promotion and promotion of the long tail video resources. The management expenses include the corresponding management behavior and the corresponding operation The cost of the use of hardware and software resources, such as salary bonuses for managers, hardware and other hardware and other venues related to the server and server costs.

Accordingly, the long-tailed resources of the operating income and operating costs can be briefly expressed as:

Revenue $=$ advertising business income + paid business income + copyright business income

Operating costs $=$ sales costs + management fees + financial costs + depreciation

In other words, increase operating income, reduce operating costs, is to expand the long tail video resources for the video site profitability considerations.

\section{Conclusions and recommendations}

How to increase sales, management and financial costs by optimizing business models and management methods, increase revenue for advertising, paid business and copyright businesses, and how to achieve strategic development in the long term, Key issues of resource profitability. This paper proposes the following recommendations. 


\section{Integrate existing resources, improve the database information}

Content is the media industry chain of scarce resources, it is the core of the development of video sites. Video site content advantage, is the enterprise influence and profitability of the fundamental source. Enterprises should give full play to the profitability of the content resources, it is necessary to effectively integrate their own resources, find out the number of its own digital assets, quantity, copyright and cooperation and so on.

Improve the database information, the composition of the existing assets and effective use of the way to carry out analysis and research, first, is conducive to enterprise research and use of existing resources, clear their own core competitiveness and core competitiveness of the direction; Enterprises based on existing resources for planning and further layout, lay the foundation for future development, to achieve the effective use of related costs; third is conducive to enterprises will own assets and user participation mechanism, the use of large data for analysis and decision-making basis.

\section{Optimize the search and recommendation engine, the use of large data analysis accurate delivery}

In the explosive growth of the number of video resources in the network environment, the user faces non-target resources far more than the target resources, both for users or service providers; resource utilization efficiency has a lot of room for improvement.

Optimize the search and recommendation engine, one can help the site to tap the use of long tail resources, long tail resources will be accurately transported to the target user's line of sight, increase short-term sales revenue and improve the user experience, the establishment of customer loyalty; The second is to help the site to understand the customer, statistics customer needs and preferences of the composition and changes to better understand and develop the market; third is to help develop customers, to induce customers to find their own interests, and then expand the market; In the consumer's behavior through the customer, better classification and collation of the database, to promote the enterprise's long-tail resource market potential mining.

\section{The use of Matthew effect, change tail for the head}

The "Matthew Effect" proposed by Robert Morton, a scientist of American history of science, in the 1960s, describes the following psychosocial phenomena: Scientists who are notorious are often more prestigious than those who are not known. Achievements are similar. Similarly, in the same project, the reputation is usually given to those who have been well-known researchers. The stronger the strength, the weaker the weak, is widely observed in various industries, and then summed up as any individual, group or region, once in a certain area of success and progress, it will produce a cumulative advantage, There will be more opportunities to achieve greater success and progress.

Network video transmission has a significant Matthew effect. Although the video users have the freedom to choose the product, but for the instinct of the instinct, attention is more easily guided by the public opinion of the video. And the public opinion of the video browsing, discussion and reprint the number of increasing and attract more attention, public opinion is growing, has become a hot spot or even focus. For the video site, seize the opportunity to create public opinion through the manufacture of users, and then use the Matthew effect will be long tail products into a focused head, one is to help enterprises to fully develop the use of existing long tail resources, driven by the enterprise inventory value And then excavation, the second is to help enterprises as the source of the topic of market opportunities, expand the visibility and market share. While the expansion of the size of Internet users to make it easier to attract capital, and further enhance their own strength.

\section{Reshaping the Industrial Chain and Exploring New Business Models}

The future media groups will be between the systemic industry chain and business model of competition, rather than just content, products or channels and other local links hard. If you want to long-term development of video sites, we must re-examine the new industrial value chain, according 
to their own resources and advantages, to seek vertical or horizontal integration of the upstream and downstream industry chain.

At present, many video sites related enterprises have made according to their own basic characteristics of the attempt, such as music as content products, to the Internet TV, smart phone terminals and other hardware product layout; beeps and miles of bass video network is for its user characteristics Mobile games business; Tencent video in the development of Tencent microblogging sluggish circumstances, will be more energy into the video and WeChat, Tencent news platform and docking, and IP content increased investment; there are some Video companies, such as the traditional media content production team, game companies and even financial companies, in the development of video sites to see the opportunity to start the video site related business development, such as participation in the production of copyright products, Promotion, investment and so on.

Although the video site business after more than ten years of development, compared with the original platform has undergone tremendous changes, the integration of more features, but overall, the video site video business and other business depth of all-round integration transformation Has just started in the future integration of the transformation of the road, there are many factors, how to make full use of national policies, combined with their own advantages in resources, according to local conditions to the existing business and business model innovation, industrial chain to extend the combination of multi- Must face and solve the problem, but also determine the key to further development of enterprises.

\section{References}

[1] Chen Lidan, Huo Qian: Long-tailed Theory of Internet Communication and Dissemination of Minorities, Journal of Southwest University for Nationalities (Humanities and Social Sciences) Vol. 04, pp. 148-152, 2013.

[2] Chris Anderson: Long tail theory, translated by Qiao Jiangtao, Beijing: CITIC Publishing House, 2009.

[3] Tong Xuena, Li Silu: On China's digital music communication strategy at long tail era, Seeking 2014, 09, pp. 187-191.

[4] Wang Chonglu: How to explore and activate the video long tail market, Communication Enterprise Management, Vol. 02, pp. 58-60, 2012.

[5] Zeng Zhen, Zhu Yanhan: Youku - a Chinese video website with long tail, Science and Technology Monthly, Vol. 12, pp. 87-88, 2007.

[6] Wei Jingzhu, Lu Jun: Long tail distribution of network works copyright management research, Library Forum, Vol.11, pp. 34-40, 2015.

[7] Gao Guowu, Lian Zhe: On the development of television long tail market in the new media environment, Journal of International Communications, Vol.02, pp. 38-46, 2013. 